Hrn. E., anfangs nur arsenigsaures Kupferoxyd; erst durcb Kochen mit der, freie Essigsüure enthaltenden Mutterlauge bildet sich das schön grüne Doppelsalz. Die Farbe lesselben iu unzerriebeuen Zustande ist um so schöner, je grölser die Krystïllchen sind; zerrieben haben alle $\mathrm{Va}$ rictäten denselben Farbenton.

Das Schwcinfurter Grün ist an der Luft anveriinderlich und in Wasser ganz unlöslich, wird aber, lange mil Jemselben gekocht, bräunlich, vermuthlich durch Verlust von Essigsỉurc. Säuren zersetzen es unter Abscheidung Jer arseuigen Säure; Ammoniak löst es mit ticf blauer Farbe vollkommen.' Alkalien, wie Kali, Natron, Kalk und Baryt, scheiden blaues Kupferoxydhydrat ab, das sich aber bald darauf in schwarzes Oxyd, und dann in rothes Oxydul verwandelt, letzteres durcb Einwirkung ler arsenigen Säure, dic dabei in Arsensäure übergeht. Aus dem so mit Kali erhaltenen Oxydul, nachdem es durch Glühen wieder in Oxyd verwandelt worden, hat Hr. Ehrmann ebenfalls den Kupfergehalt dieses Doppelsalzes bestimmt. (Bulletin de la Société de Mühlhausen, No. 31 p. 68.)

XLIV. Ueber eine verbesserte Constrution von Lufipurnpen; von Dr. Friedrich Mohr in Coblenz.

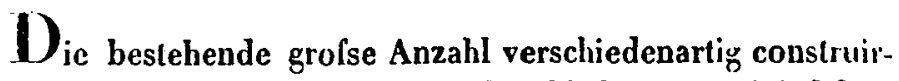
ter Luftpumpen kann mich nicht ablialten eine Modification derselben, die ich für eine Verbesserung balte, mitzutheilen. Es wird dieselbe um so mehr die Aufmerksamkeit der Physiker in Anspruch vebmev, als sie durch cinen höchst einfachen Mechanismus den schädlichen Raum ganz vermeidet, und aufscrdem melurere Vortheile besilut, die mit diesem Umstande im Zusammenhange stehen. 
Die Maschine (Fig. 2 Taf. V) gehürt zu der Art der doppeltwirkenden oben geschlossenen. Der Stiefol $A B$ ist oben und unten flach abgescbliffen, so dafs unmittelbar die flachen Endstücke, mit etwas Fett daran, durch Schrauben befestigt werden. In beiden Endstükken befinden sich Kegelventile $m$ und $n$, nach aufsen beweglich, von denen das obere $m$ durch sein eigenes Gewicht, das untere $n$ aber durch eine aufwärts wirkende Feder angedrückt wird. Der massive Kolben $k$ ist an beiden Enden ganz flach, und bewegt sich mit einer genau cylindrischen Stange luftdicht durch die Stopfbüchse $b b$. An den Endstücken befinden sich aufserdem dic von innen nach aufseu sich verengernden konischen Oeffnungen $o$ und $p$, worin dic Enden des Stangenventils $e f$ luftclicht einpassen. Die an 0 und $p$ befestigten Leitungsröluren fübren von $g$ an gemeinschaftlich zum Recipienten. Das Stangenventil ef bewegt sich mit barter Reibung luftdicht durch den Embolus $k$.

Wenn nun zuerst der Kolben ron oben nach unten bewegt wird, so zieht er die Stange ef anfangs mil; dadurch wird die Oeffnung $o$ frei und dic Luft strömt aus dem Recipienten iu den Stiefel; so wie aber das untere Ende der Stange ef die konische Oeffnung bei $p$ geschlossen bat, ist der Kolben genöthigt uber die Stange wegzugleiten. Die im Kolben enthaltene atmosphärische Luft ist durch das Ventil $\boldsymbol{n}$ entfernt worden. Beim Rückgange des Kolbens nach oben wird zuerst die Oeffoung bei $p$ frei und die bei $o$ geschlossen, und die bei der ersten Verdünnung in den Sliefel gebrachte Luft wird durch das Ventil $m$ entfernt. Da nun die Stange ef die Oeffnung $o$ schliefst ehe die Luft im Stiefel eine bemerkbare Dichte erlangt hat, so bleibt die Luft hinter $o$ anfangs verdünnt abgeschlossen, wird aber selbst durch ihre Verbindung mit $p$ verdünnt. Bei dem wechselnden $S_{p}$ iel des Kolbens sieht man leicht, dafs die Verdünnung bis in's Unendliche gehen kaun, wenu Sorge getragen ist, 
dafs sich die Flächen des Kolbens und der Endstiiclie genau berühren, und dafs die Kegclventile $m$ und $n$, so wie die Enden der Stange ef genau ihre Oeffnungen ausfüllen. Der erste Kolbenzug mufs offenbar der beschwerlichste seyn; jeder folgende wird immer leichter, weil der Druck der Atmosphäre immer später zu überwinden seyn wird, so dafs er sich bei bedeutender Evacualion fast nur auf die Reibung des Kolbens beschränken wird. Der atmosphürische Druck auf die Dicke der Kolbenstange, der an sich unbedeutend ist, wird sich dann beim Aufund Niedergange, so wie bei zwei Stiefeln gleichzeitig compensiren.

Zu einer noch einfacheren Construction einer doppeltwirkenden Luftpumpe gab mir Ritchie's Idee Veranlassung, welche in Gehler's phys. Wörterbuch, neuc Bearbeit., Bd. VI 1 Abth. S. 578, beschrieben ist. Hierbei ist jedoch nicht klar, wie der Embolus bis unter die Communicationsröhre binabgedrückt werden kann, wemn sich nicht im Boden des Stiefels ein Ventil oder ein Hahn belindet, die übrigeus dabei hartnäckig vermieden werden. Das glücklichste Princip dabei besteht darin, dafs die Mündung der Verbindungsröhre unmittelbar in cylindrischen Theile des Stiefels angebracht ist; und zwar so weit von dem Ende desselben, dals der Kolben den Raum unterhalb derselben genau ausfüllt.

In Fig. 3 Taf. V $A B$ ist der Stiefel; seitwärts befinden sich darin bei $q$ und $r$ kleine Oeffnungen, in Verbindung mit den einfach durchbohrten Hähnen $s$ und $t$, welche gemeinschaftlich bei $h$ gesteuert werden. Es befinde sich nun der Kolben oben, der Hahn s sey geöffnet, $t$ aber geschlossen, so wird durch Hinabdrücken des Kolbens die Verdünnung durch $s$ erfolgen, und die atmosphärische Luft durch $n$ entweichen. Bei $r$ wird ein kleiuer schädlicher Raum abgeschlossen, welcher sich, wenn der Kolben an ihm vorbei ist, in den Stiefel, und durch $s$ aucb in den Recipienten verbreiten wird. Nun wer- 
den die Häbne gedrebt, so dafs $t$ offen und $s$ verschlossen ist, und die bei der ersten Verdünnung in den Stiefel gelangte Luft wird durch $m$ entleert. Der schädliche Raum bei $q$ wird sich nun ebenfalls dem Stiefel und durch $t$ auch dem Recipienten mittheilen. Es wird aber endlich ein Punkt der Verdünnung kommen, wo der Kolbeu an den Oeffnungen $q$ und $r$ vorbeigegangen seyn wird ehe die Luft im Stiefel die Dichtigkeit der atmosphirischen erlangt hat, und von diesem Punkt an werden die schädlichen Räume bei $q$ und $r$ mit verdünnter Luft abgesperit, wodurch also dem Princip nach eine unendliche Verdünuung möglich ist.

Die eiufachste Construction einer Luftpumpe, dic zugleich sehr kräftig wirken mufs, scheint uir folgende in Fig. \& Taf. V abgebildele zu seyn.

Es befindet sich auf der Mitte der Höbe des Sticfels eine einzige Oeffnung $i$, durch den einfach durchbohrten Hahn $p$ zu reguliren. Alles andere ist wie bei der so eben beschriebenen Maschine, und das Spiel der Evacuation folgendes. Der Hahn $p$ ist während jeder Bewegung des Kolbens geschlossen. Wird der Kolben hinabgestofsen, so mufs der ganze Stiefel luftleer werden, und durch eine kurze Oeffaung des Hahns tritt die Luft in den Stiefel. Der Hahu wird sogleich wieder geschlossen und der Kolben aufwärts bewegt, wobei er die Luft der ersten Verdünnung durch $m$ austreibt. Es wird nun wiederum der Hahn einen Augenblick geöffnet und so weiter. Durch eine Selbststeuerung kann man es leicht erlangeu, dals sich der Hahn dann offinet, wenn der Kolben eben vor der Oeffnung $i$ ist, wodurch man sowobl des Oeffnens, als auch des Abwartens der gleichmäfsigen Vertreibung überhoben ist. Der schädliche Raum bei $i$ wird aus denselben Gründen wie bei Fig. 3 Taf. V verschwinden, allein bei dieser Maschine viel früher, weil die Oeffnung $i$ dem Anfangspunkt der Bewegung des Kolbeus näher liegt, wodurch also schueller eine verdünute 
Luft bei $i$ abgeschlossen wird. Dic Vorzüge dieser Maschine sind vielfach.

1) Die Construction ist selr einfach, und kann dadurch sehr dauerbaft seyn. Der Kolben ist mnssiv, die Endstücke sind starke flache Messingscheiben, an deven durch Fleifs jeder schädliche Ram! vermieden werden kann.

2) Der schädliche Raum kann wegen der cylindrischen Gestalt des Stiefels sehr klein gemacht werden; im Verlaufe der Verdünnung verschwindet er aber vollständig, so dafs er den Namen eines schäulicben Raumes ganz verliert.

3) Die Verdünuung kann ex principio in's Uuendliche gehen.

4) Der Kraftaufwand wird mit jeder folgenden Bewegung geringer.

5) Bei jeder Bewegung des Kolbens entstebt eine Verdünnung.

6) Die Steuerung ist sehr einfach; entweder ein einfach durchbohrter Hahn, und auch dieser kaun weggelassen werden, oder wemn er vorbanden ist, immer geöffnet bleiben, wobei die Verdünnung zwar etwas langsamer, aber doch in's Unendliche fortgehen kann, so dafs diese Maschine obne Selbststeuerung, olne Steuerung durch den Experimentator, durch die blofse Bewegung des Kolbens in's Unendliche verdünnt, was bis jetzt von keiner Maschine geleistet worden ist.

\section{Diamanten in Algier.}

Durch Hrn. Peluzo, Sardinischen Consul in Algier, sind kürzlich daselbst von eineın Eingebornen drei Diamanten aufgekauft, welche in dem goldbaltigen Sande des Flusses Gumel in der Provinz Constantine gefunden wurden. Den einen erstand Hr. Dufrénoy, die beiden andern Hr. Brogniąrt für das Museum und für die Sammlung dés Hrn. de Drée. Bisher sind noch nie Diamanten in Afrika aufgefunden (Bullet. de la Soc. Géol. IV p. 164). 